\title{
RESEARCH
}

Open Access

\section{Neoadjuvant chemotherapy followed by hyperthermic intraperitoneal chemotherapy for patients with colorectal peritoneal metastasis: a retrospective study of its safety and efficacy}

Sicheng Zhou ${ }^{\dagger}$, Yujuan Jiang ${ }^{\dagger}$, Jianwei Liang* ${ }^{*}$, Wei Pei ${ }^{*}$ and Zhixiang Zhou

\begin{abstract}
Background: Cytoreductive surgery (CRS) and hyperthermic intraperitoneal chemotherapy (HIPEC) are effective routine treatments for colorectal peritoneal metastasis (PM). However, the safety and efficacy of neoadjuvant chemotherapy (NAC) before CRS+HIPEC are poorly understood. Therefore, this study aimed to assess the perioperative safety and long-term efficacy of NAC prior to CRS+HIPEC for patients with synchronous colorectal PM.

Methods: Patients with synchronous colorectal PM who received NAC prior to CRS+HIPEC were systematically reviewed at the China National Cancer Center and Huanxing Cancer Hospital from June 2017 to June 2019. The clinicopathologic characteristics, perioperative parameters, and survival rates of patients who underwent CRS+HIPEC with NAC (NAC group) and patients who underwent CRS+HIPEC without NAC (non-NAC group) were compared.

Results: The study enrolled 52 patients, with 20 patients in the NAC group and 32 in the non-NAC group. In the NAC group, the proportion of patients with a peritoneal carcinomatosis index (PCI) score $<12$ was significantly higher than that in the non-NAC group $(80.0 \%$ vs $50.0 \%, P=0.031)$, and more patients achieved complete cytoreduction ( $80.0 \%$ vs $46.9 \%, P=0.018)$. The two groups had comparable grade III/IV complications and similar reoperation and mortality rates $(P>0.05)$. However, patients who received NAC had lower platelet counts (151.9 vs $197.7 \times 10^{9} / \mathrm{L}, P=0.036$ ) and neutrophil counts (4.7 vs $7.2 \times 10^{9} / \mathrm{L}, P=0.030$ ) on postoperative day 1. More patients survived for 2 years in the NAC group than in the non-NAC group (67.4\% vs $32.2 \%$, respectively, $P=0.044$ ). However, the completeness of cytoreduction score (HR, 2.99; 95\% Cl, 1.14-7.84; $P=0.026)$, rather than NAC, was independently associated with overall survival (OS) in the multivariate analysis after controlling for confounding factors.

\footnotetext{
* Correspondence: Liangjw1976@163.com; peiweifbwk@163.com †Sicheng Zhou and Yujuan Jiang contributed equally to this work. Department of Colorectal Surgery, National Cancer Center/National Clinical Research Center for Cancer/Cancer Hospital, Chinese Academy of Medical Sciences and Peking Union Medical College, No. 17 Panjiayuan Nanli, Chaoyang District, Beijing 100021, China
}

(c) The Author(s). 2021 Open Access This article is licensed under a Creative Commons Attribution 4.0 International License, which permits use, sharing, adaptation, distribution and reproduction in any medium or format, as long as you give appropriate credit to the original author(s) and the source, provide a link to the Creative Commons licence, and indicate if changes were made. The images or other third party material in this article are included in the article's Creative Commons licence, unless indicated otherwise in a credit line to the material. If material is not included in the article's Creative Commons licence and your intended use is not permitted by statutory regulation or exceeds the permitted use, you will need to obtain permission directly from the copyright holder. To view a copy of this licence, visit http://creativecommons.org/licenses/by/4.0/. The Creative Commons Public Domain Dedication waiver (http://creativecommons.org/publicdomain/zero/1.0/) applies to the data made available in this article, unless otherwise stated in a credit line to the data. 
(Continued from previous page)

Conclusion: NAC administration before CRS+HIPEC can be regarded as safe and feasible for patients with colorectal PM with comparably low mortality rates and acceptable morbidity rates. Nevertheless, large-sample randomized controlled studies are needed to confirm whether the administration of NAC before CRS+HIPEC confers a survival benefit to patients.

Keywords: Cytoreductive surgery, Hyperthermic intraperitoneal chemotherapy, Colorectal cancer, Peritoneal metastases, Neoadjuvant chemotherapy

\section{Introduction}

The peritoneum is the second most common site of colorectal cancer (CRC) metastasis after the liver [1], and $5-15 \%$ of CRC patients exhibit evidence of synchronous peritoneal metastasis (PM) [2, 3]. PM is well known to be an indicator of poor prognosis, and the median survival time of patients with PM is only 5-7 months [4]. Cytoreductive surgery (CRS) combined with hyperthermic intraperitoneal chemotherapy (HIPEC) has been carried out at experienced centres for select patients after extensive exploration and has become the cornerstone therapeutic strategy aiming to cure PM of CRC origin [5-7]. For selected patients, the median survival can reach approximately 40 months after CRS and HIPEC treatment for PM arising from CRC [8].

CRS+HIPEC is a complicated and potentially lifethreatening procedure, with postoperative complication rates as high as 37.9-60.5\% [9-14], which can worsen general conditions and hamper subsequent systemic adjuvant chemotherapy. Therefore, systemic adjuvant chemotherapy should be arranged before surgery whenever possible. Nevertheless, neoadjuvant chemotherapy (NAC) has been shown to benefit the survival of patients with stage IV CRC [15]. Relevant studies have also demonstrated that NAC before CRS+HIPEC is safe for CRC patients with PM and can provide certain survival benefits $[16,17]$. On this basis, we performed a single-centre retrospective study to investigate the survival benefits of NAC prior to CRS+HIPEC as well as its perioperative safety for CRC patients with PM.

\section{Patients and methods}

The present study included 52 eligible patients with synchronous PM arising from CRC who underwent CRS+ HIPEC at the National Cancer Center and Huanxing Cancer Hospital between June 2017 and June 2019. The inclusion criteria included the following: (1) pathologically confirmed CRC, (2) aged between 18 and 75 years, and (3) Eastern Cooperative Group (ECOG) score $\leq 1$. The exclusion criteria were as follows: (1) the presence of other malignant tumours, (2) palliative surgery such as bypass surgery or simple ostomy, (3) emergency operation, and (4) NAC administration for fewer than 3 cycles. The study protocol was approved by the Ethics
Committee of the Cancer Hospital at the Chinese Academy of Medical Sciences (NCC 2017-YZ-026, Oct 17, 2017).

Patients were divided into two groups: those who received NAC followed by CRS+HIPEC (NAC group) and those who underwent CRS+HIPEC first without NAC (non-NAC group). Preoperative demographic and clinical information from the two groups was prospectively collected into an institutional database and retrospectively analysed. The treatment strategies for each patient were determined based on their wishes by multidisciplinary team meetings that incorporated radiologists and medical and surgical oncologists. In principle, CRS+ HIPEC is typically used first for patients with resectable PM according to National Comprehensive Cancer Network (NCCN) guidelines. Conversely, systemic chemotherapy is often used for patients with extensive systemic metastases not subjectable to $\mathrm{CC} 0-1$ resection. The peritoneal carcinomatosis index (PCI) was used to assess the degree of PM, which was scored from 0 to 3 for each of the 13 defined areas of the abdominal cavity [18]. Intraoperative laparoscopic exploration was performed to calculate the PCI scores after NAC. The completeness of cytoreduction (CC) score was recorded as

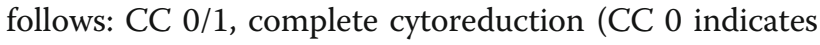
no visible disease and $\mathrm{CC} 1$ indicates nodules smaller than $0.25 \mathrm{~cm}$ ); and $\mathrm{CC} 2 / 3$, incomplete cytoreduction (CC 2 indicates a nodule size between 0.25 and $2.5 \mathrm{~cm}$ and CC 3 indicates nodules larger than $2.5 \mathrm{~cm}$ ) [19]. Toxicity indexes of chemotherapy (blood, liver, and kidney toxicity), including the neutrophil count, platelet count, ALT level, and creatinine level, were measured in the morning on postoperative days (PODs) 1,3 , and 5 . Postoperative complications were recorded and staged according to the Common Terminology Criteria for Adverse Events (CTCAE) classification within 30 days [20].

\section{CRS+HIPEC procedure}

The CRS+HIPEC procedure has been described previously [21]. All patients received HIPEC via a closed technique after cytoreduction and to fashioning of the intestinal anastomoses. Oxaliplatin $\left(200 \mathrm{mg} / \mathrm{m}^{2}\right)$ and raltitrexed $\left(3 \mathrm{mg} / \mathrm{m}^{2}\right)$ with or without lobaplatin $(50 \mathrm{mg} /$ $\mathrm{m}^{2}$ ) were used for intraperitoneal chemotherapy. All 
patients were treated with a mixed solution of chemotherapeutic agents and $3 \mathrm{~L}$ of saline solution in the abdominal and pelvic cavities for $60 \mathrm{~min}$ at $42-43{ }^{\circ} \mathrm{C}$. Thereafter, four catheters remained in the original position, and two more HIPEC procedures with the same chemotherapeutic regimens as well as perfusion times were reperformed on the second and fourth days after surgery in the ward. CRS+HIPEC treatment was performed by two surgical specialists with more than 20 years of experience in gastrointestinal surgery at the two centres; the exact same HIPEC technique and postoperative treatment were performed at both centres.

\section{Follow-up}

All patients were scheduled to receive follow-up through outpatient visits every 3 months for the first 3 years and then every 6-12 months for the 3 years thereafter. CT scans of the abdomen and pelvis and laboratory examinations, including those of tumour biomarkers (CEA and CA 19-9), were performed at every follow-up. The long-term endpoint of this study was the 3-year overall survival (OS) rate. OS was defined as the time from the date of surgery until death or the last follow-up (July 31, 2020).

\section{Statistical analysis}

All variables were compared between the groups using IBM SPSS Statistics software version 24.0 (IBM Corp, Armonk, NY, USA). Continuous variables are presented as the mean $\pm \mathrm{SD}$ and were analysed with Student's $t$ tests or Mann-Whitney $U$ tests depending on the distribution. Differences between fractions were analysed by $\chi^{2}$ tests or Fisher's exact tests as appropriate. Actuarial OS was estimated by the Kaplan-Meier method. Univariate analysis of variables potentially impacting OS was performed with the log-rank test, and significant univariate variables were applied in the multivariate Cox regression model. A $P$ value lower than 0.05 was regarded as statistically significant.

\section{Results}

In the present study, 52 patients with synchronous PM arising from CRC underwent CRS+HIPEC; 20 (38.5\%) received NAC, and 32 (61.5\%) underwent surgery without receiving NAC. Patients in the NAC group were treated with a chemotherapy regimen commonly used for CRC, and 6 patients received the antiangiogenic agent bevacizumab, as shown in Table 1 . The patient demographics and clinical details are provided in Table 2. In the NAC group, $80.0 \%$ of the patients achieved complete cytoreduction (CC $0 / 1)$, versus $46.9 \%$ in the non-NAC group $(P=0.018)$. In addition, the proportion of patients with a PCI score $<12$ in the NAC group was significantly higher than that in the non-NAC group
Table 1 Neoadjuvant chemotherapy regimens for 20 patients

\begin{tabular}{ll}
\hline Preoperative chemotherapy regimens & $\boldsymbol{N}(\%)$ \\
\hline XELOX & $5(25.0)$ \\
XELOX+bevacizumab & $2(10.0)$ \\
FOLFOX & $5(25.0)$ \\
FOLFIRI & $3(15.0)$ \\
FOLFOX+bevacizumab & $2(10.0)$ \\
FOLFIRI+bevacizumab & $2(10.0)$ \\
5-FU+leucovorin & $1(5.0)$ \\
\hline
\end{tabular}

XELOX capecitabine+oxaliplatin, FOLFOX leucovorin calcium +5-

fluorouracil+oxaliplatin, FOLFIRI leucovorin calcium+5-fluorouracil+irinotecan

( $80.0 \%$ vs $50.0 \%, P=0.031$ ). There were no significant differences between the two groups in terms of age, sex, body mass index, preoperative CEA level, comorbidity, tumour location, histology, T stage, N stage, liver metastases, ascites, HIPEC regimen, or adjuvant chemotherapy.

Table 3 lists the surgical outcomes and postoperative course. The mean operative time in the NAC group was shorter than that in the non-NAC group, but the difference was not statistically significant ( 245.5 vs $289.4 \mathrm{~min}$, $P=0.082$ ). With regard to toxicity indexes after HIPEC, patients in the NAC group were more likely to experience thrombocytopenia after HIPEC than those in the non-NAC group $(30.0 \%$ vs $6.3 \%, P=0.043)$. There were no significant differences in the rates of grade III/IV complications $(40.0 \%$ vs $31.3 \%, P=0.519)$, hospital stay length (15.4 vs 13.9 days, $P=0.333$ ), or 30 -day reoperation rate $(1.9 \%$ vs. $0 \%, P=1.000)$ between patients in the NAC and non-NAC groups.

In addition, the mean platelet count (151.9 vs $197.7 \times$ $\left.10^{9} / \mathrm{L}, P=0.036\right)$ and leukocyte count (4.7 vs $7.2 \times 10^{9} /$ $\mathrm{L}, P=0.030$ ) in the NAC group were also significantly lower than those in the non-NAC group on POD 1 (Fig. 1 and Fig. 2). The ALT and creatinine levels on PODs 1, 3 , and 5 were not statistically different between the two groups (Fig. 3 and Fig. 4).

\section{Survival analysis}

The median follow-up time was 18.5 (range, 3-28) months, and 3 patients were lost to follow-up. During the follow-up period, 28 patients died of tumour recurrence and metastasis, including 6 in the NAC group and 22 in the non-NAC group. The median survival for all patients was 24 months, and the estimated 1- and 2-year OS rates for the entire cohort were $65.0 \%$ and $42.1 \%$, respectively (Fig. 5). Patients who received NAC prior to CRS+HIPEC had a higher 2-year OS rate than those who underwent CRS+HIPEC without NAC (32.2\% vs $67.4 \%, P=0.044$ ) (Fig. 6).

The results of exploratory univariate and multivariate Cox regression analyses of OS are detailed in Table 4 . 
Table 2 Clinical characteristics of the 52 enrolled patients

\begin{tabular}{|c|c|c|c|c|}
\hline Variable & All patients $(n=52)$ & NAC $(n=20)$ & Non-NAC $(n=32)$ & $P$ \\
\hline Age (years) & & & & 0.350 \\
\hline$<65$ & $35(67.3)$ & $15(75.0)$ & $20(62.5)$ & \\
\hline 65 & $17(22.7)$ & $5(25.0)$ & $12(37.5)$ & \\
\hline Gender & & & & 0.508 \\
\hline Male & $29(55.8)$ & $10(50.0)$ & $19(59.4)$ & \\
\hline Female & $23(44.2)$ & $10(50.0)$ & $13(40.6)$ & \\
\hline Body mass index $\left(\mathrm{kg} / \mathrm{m}^{2}\right)$ & $22.5 \pm 3.5$ & $22.8 \pm 3.3$ & $22.4 \pm 3.6$ & 0.542 \\
\hline Preoperative CEA level (ng/ml) & & & & 0.744 \\
\hline$<5$ & $17(32.7)$ & $6(30.0)$ & $11(34.4)$ & \\
\hline$\geq 5$ & $35(67.3)$ & $14(70.0)$ & $21(65.6)$ & \\
\hline Comorbidity & $14(26.9)$ & $4(20.0)$ & $10(31.3)$ & 0.374 \\
\hline Tumour location & & & & 0.636 \\
\hline Colon & $42(80.8)$ & $15(75.0)$ & $27(84.4)$ & \\
\hline Rectum & $10(19.2)$ & $5(25.0)$ & $5(15.6)$ & \\
\hline Histology & & & & 0.289 \\
\hline Adenocarcinoma & $29(55.8)$ & $13(65.0)$ & $16(50.0)$ & \\
\hline Mucinous/signet-ring & $23(44.2)$ & $7(35.0)$ & $16(50.0)$ & \\
\hline T stage & & & & 0.287 \\
\hline T3 & $6(11.5)$ & $4(20.0)$ & $2(6.3)$ & \\
\hline T4 & $46(88.5)$ & $16(80.0)$ & $30(93.7)$ & \\
\hline N stage & & & & 0.506 \\
\hline No & $8(15.4)$ & $3(15.0)$ & $5(15.6)$ & \\
\hline N1 & $16(30.8)$ & $8(40.0)$ & $8(25.0)$ & \\
\hline N2 & $28(53.8)$ & $9(45.0)$ & $19(59.4)$ & \\
\hline $\mathrm{PCl}$ score & & & & 0.031 \\
\hline$<12$ & $32(61.5)$ & $16(80.0)$ & $16(50.0)$ & \\
\hline$\geq 12$ & $20(38.5)$ & $4(20.0)$ & $16(50.0)$ & \\
\hline $\mathrm{PCl}$ score & $11.9 \pm 5.6$ & $9.8 \pm 4.7$ & $13.7 \pm 6.4$ & 0.006 \\
\hline Liver metastases & $9(17.3)$ & $4(20.0)$ & $5(15.6)$ & 0.977 \\
\hline Ascites & $22(42.3)$ & $8(40.0)$ & $14(43.8)$ & 0.790 \\
\hline HIPEC regimen & & & & 0.930 \\
\hline Lobaplatin+oxaliplatin+raltitrexed & $23(44.2)$ & $9(45.0)$ & $14(43.8)$ & \\
\hline Oxaliplatin+faltitrexed & $29(55.8)$ & $11(55.0)$ & $18(56.2)$ & \\
\hline CC score & & & & 0.018 \\
\hline $0-1$ & $31(59.6)$ & $16(80.0)$ & $15(46.9)$ & \\
\hline $2-3$ & $21(40.4)$ & $4(20.0)$ & $17(53.1)$ & \\
\hline Adjuvant chemotherapy & & & & 0.738 \\
\hline Yes & $44(84.6)$ & $16(80.0)$ & $28(87.5)$ & \\
\hline No & $8(15.4)$ & $4(20.0)$ & $4(12.5)$ & \\
\hline
\end{tabular}

$P C l$ peritoneal carcinomatosis index, $C C$ cytoreduction score

The univariate analysis identified the following prognostic indicators for OS: neoadjuvant chemotherapy (HR, 0.36; 95\% CI, 0.13-0.92; $P=0.033$ ), the PCI score (HR, 2.98; 95\% CI, 1.41-6.32; $P=0.004)$, and the CC score
(HR, 4.20; 95\% CI, 1.89-9.36; $P<0.001)$. After correction for these variables in the multivariate analysis, OS was significantly associated with the CC score (HR, 2.99; 95\% CI, 1.14-7.84; $P=$ 0.026). Neoadjuvant 
Table 3 Surgical outcomes and postoperative courses of the 52 enrolled patients

\begin{tabular}{|c|c|c|c|c|}
\hline Variable & All patients $(n=52)$ & NAC $(n=20)$ & Non-NAC $(n=32)$ & $P$ \\
\hline Operative time (min, mean $\pm S D$ ) & $276.3 \pm 60.1$ & $245.5 \pm 59.1$ & $289.4 \pm 63.4$ & 0.082 \\
\hline Intraoperative blood loss ( $\mathrm{mL}$, mean $\pm \mathrm{SD}$ ) & $104.3 \pm 111.1$ & $115.0 \pm 111.3$ & $100.8 \pm 111.0$ & 0.661 \\
\hline Postoperative complication (Grades 3-4) & $18(34.6)$ & $8(40.0)$ & $10(31.3)$ & 0.519 \\
\hline Arrhythmia & $1(1.9)$ & $1(5.0)$ & $0(0)$ & \\
\hline Pneumonia & $3(5.8)$ & $2(10.0)$ & $1(3.1)$ & \\
\hline Anastomotic leakage & $3(5.8)$ & $1(5.0)$ & $2(6.3)$ & \\
\hline lleus & $7(13.5)$ & $3(15.0)$ & $4(12.5)$ & \\
\hline Abdominal abscess & $3(5.8)$ & $1(5.0)$ & $2(6.3)$ & \\
\hline Intra-abdominal haemorrhage & $1(1.9)$ & $0(0)$ & $1(3.1)$ & \\
\hline Wound infection & $5(9.6)$ & $2(10.0)$ & $3(9.4)$ & \\
\hline Toxicity indexes after HIPEC & $22(42.3)$ & $10(50.0)$ & $12(37.5)$ & 0.375 \\
\hline Abnormal changes in neutrophils & $6(11.5)$ & $3(15.0)$ & $3(9.4)$ & 0.864 \\
\hline Abnormal changes in platelets & $8(15.4)$ & $6(30.0)$ & $2(6.3)$ & 0.043 \\
\hline Abnormal changes in ALT & $8(15.4)$ & $2(10.0)$ & $6(18.8)$ & 0.463 \\
\hline Abnormal changes in creatinine & $3(5.8)$ & $1(5.0)$ & $2(6.3)$ & 1.000 \\
\hline Time to first flatus (day, mean \pm SD) & $3.8 \pm 1.8$ & $4.1 \pm 1.9$ & $3.6 \pm 1.8$ & 0.811 \\
\hline Total hospital stay (day, mean \pm SD) & $14.4 \pm 5.0$ & $15.4 \pm 6.0$ & $13.9 \pm 3.9$ & 0.333 \\
\hline Re-operation & $1(1.9)$ & $1(5.0)$ & $0(0)$ & 1.000 \\
\hline Mortality (\%) & $0(0)$ & $0(0)$ & $0(0)$ & 1.000 \\
\hline
\end{tabular}

chemotherapy (HR, 0.55; 95\% CI, 0.22-1.39; $P=0.204$ ) and the PCI score (HR, 1.49; 95\% CI, 0.61-3.66; $P=$ 0.381 ) were not independently associated with OS.

\section{Discussion}

In contrast to mucinous appendiceal neoplasms, PM from CRC is usually a manifestation of extensive tumour progression and poor prognosis. However, CRS+HIPEC can improve the long-term survival rates of well-selected patients with PM [5-8]. In addition to CRS+HIPEC treatment, perioperative systemic chemotherapy has been shown to prolong the survival of patients with PM $[15,16,22]$. However, the optimal timing of chemotherapy, especially the safety and long-term efficacy of

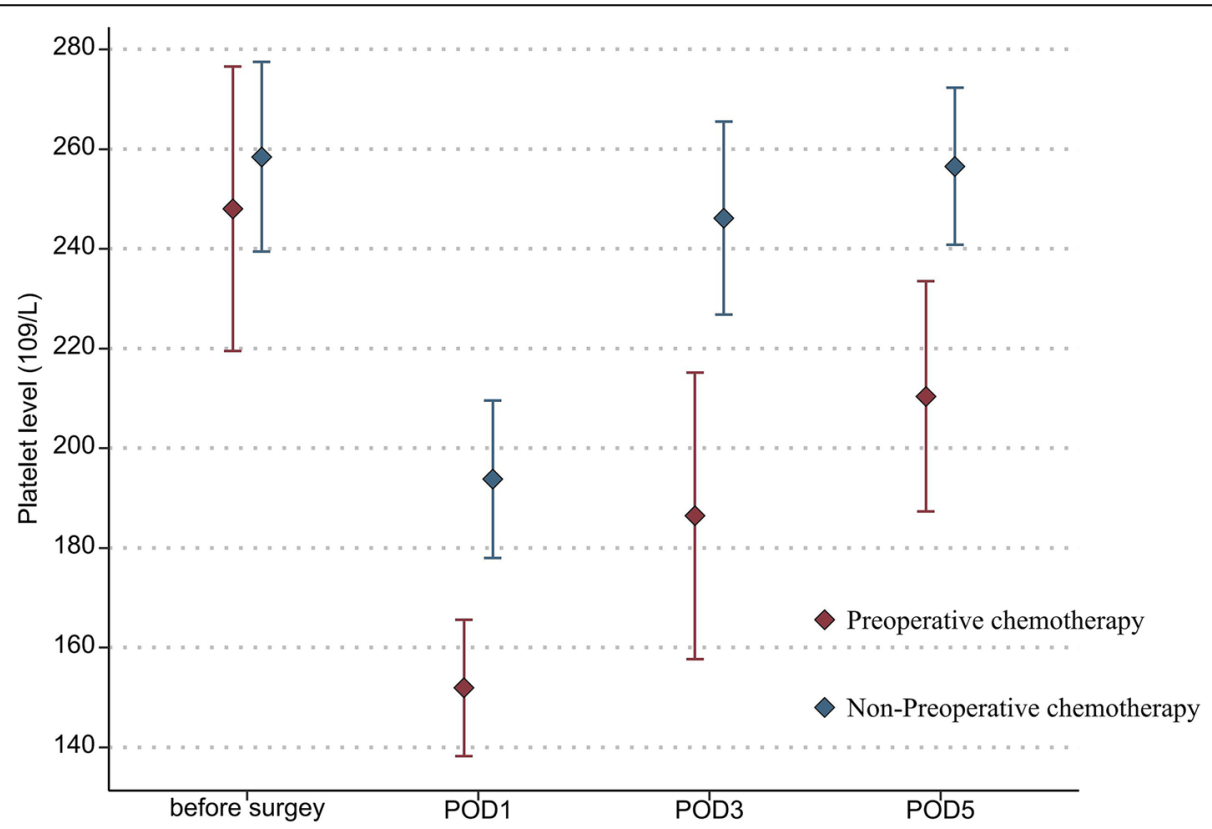

Fig. 1 Mean platelet levels in the two groups of patients before surgery and from postoperative days 1 through 5 (statistical comparison made by Student's $t$ test) 


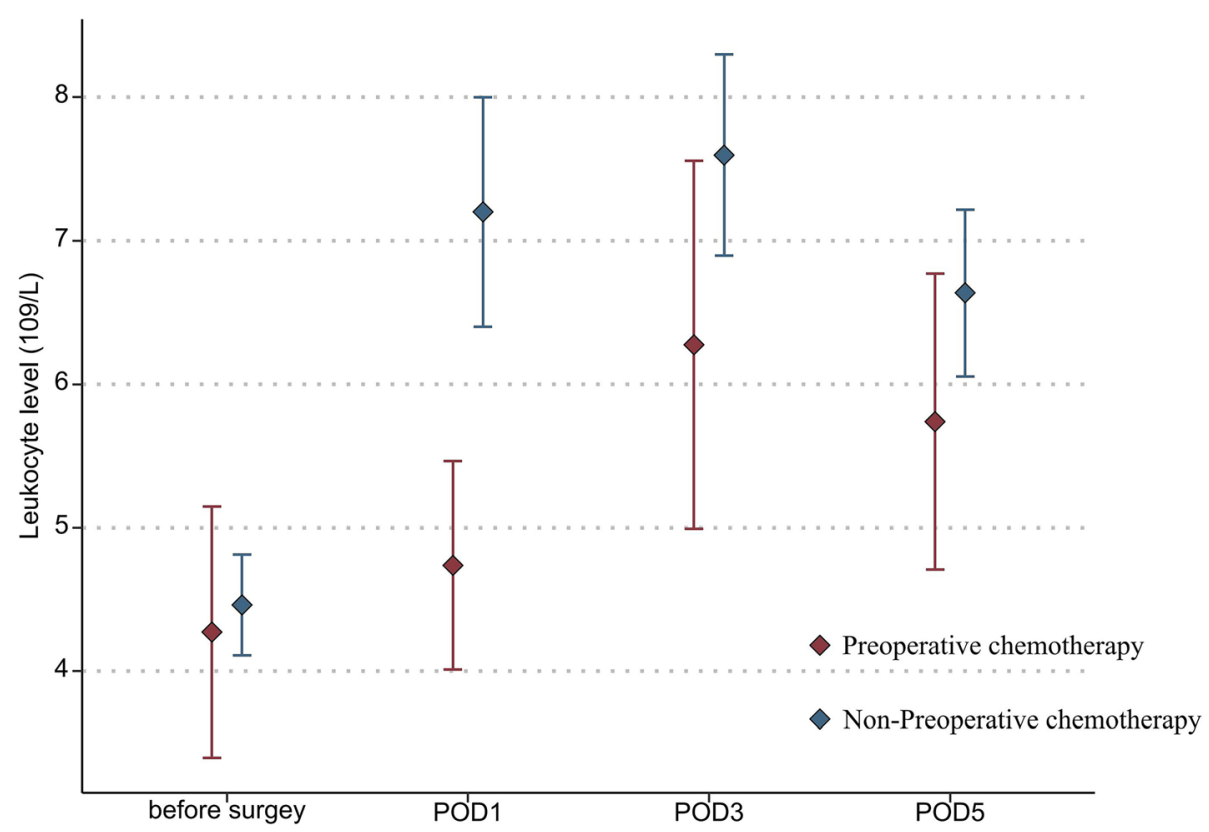

Fig. 2 Mean leukocyte levels in the two groups of patients before surgery and from postoperative days 1 through 5 (statistical comparison made by Student's $t$ test)

preoperative chemotherapy, remains unknown. Therefore, this study was conducted to investigate the perioperative safety and survival benefits of performing NAC before the CRS+HIPEC procedure for CRC patients with synchronous PM. Our data revealed that patients who underwent CRS+HIPEC following NAC had a comparably low mortality rate and an acceptable morbidity rate. Although NAC has a certain effect on platelets and neutrophils, these responses did not appear to translate to postoperative complications under close supervision and active surveillance. Nevertheless, while patients who underwent NAC experienced

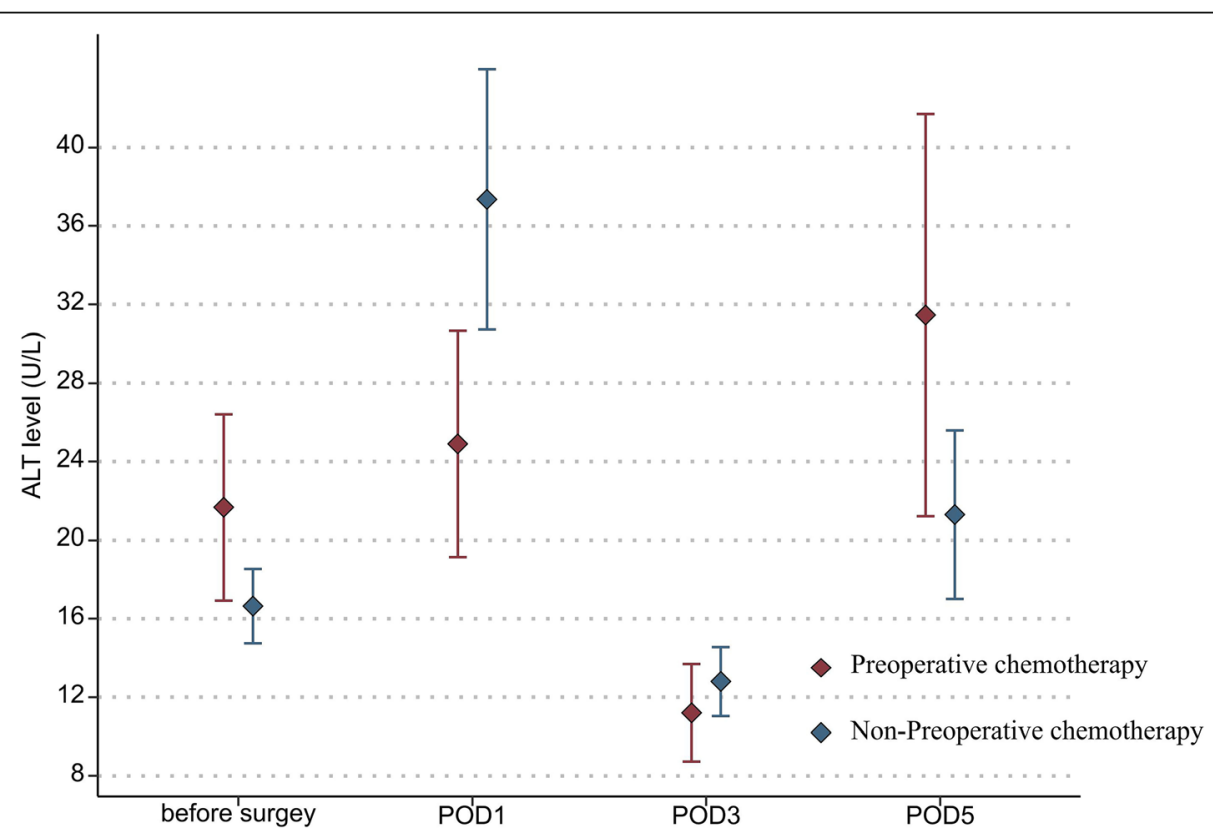

Fig. 3 Mean ALT levels in the two groups of patients before surgery and from postoperative days 1 through 5 (statistical comparison made by Student's $t$ test) 


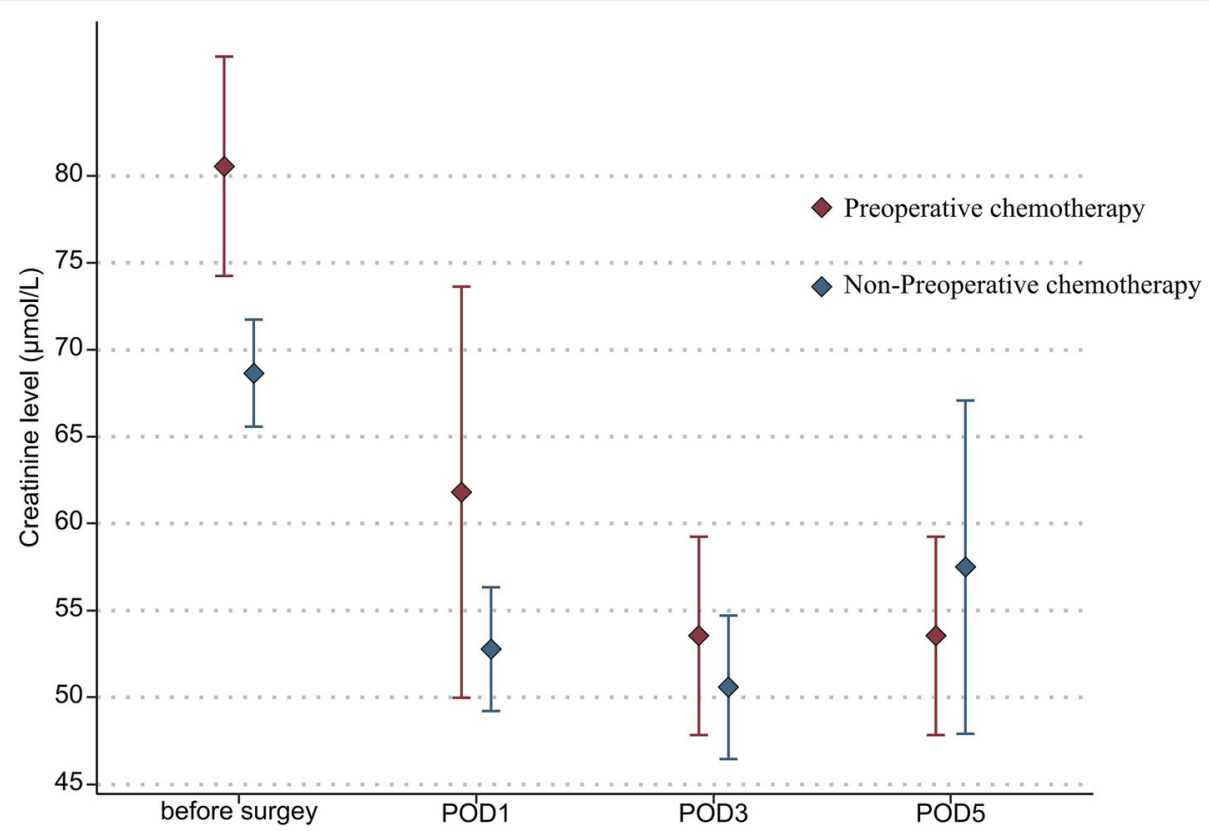

Fig. 4 Mean creatinine levels in the two groups of patients before surgery and from postoperative days 1 through 5 (statistical comparison made by Student's $t$ test)

improvements in OS compared to those who underwent only surgery, NAC was not an independent prognostic factor for improving OS after controlling for confounding factors. However, the selection of chemotherapy drugs in this study lacked a unified standard, and targeted drugs such as bevacizumab were adopted in some patients, which potentially interfered with the safety and oncological treatment efficacy of NAC.

CRS+HIPEC is a complex and potentially lifethreatening procedure that has a morbidity rate ranging from 12 to $52 \%$ and a mortality rate ranging from 0.9 to $5.8 \%$ at 10 specified international treatment centres [23].

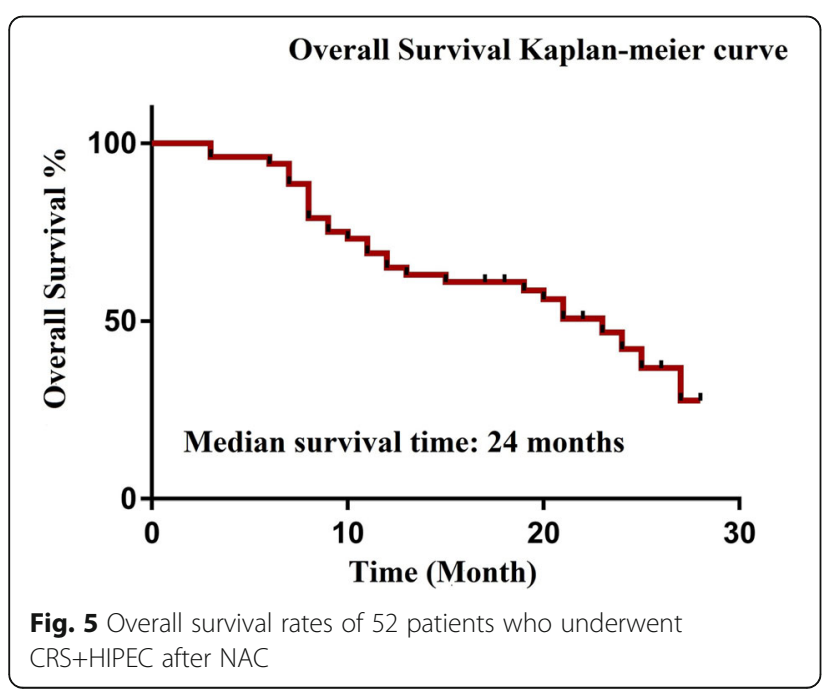

Therefore, it is worth exploring whether the side effects of NAC, such as myelosuppression, neurotoxicity, and gastrointestinal reactions, further increase morbidity and mortality rates after CRS+HIPEC. The retrospective study of Devilee et al. assessed the safety and efficacy of NAC for 91 patients undergoing CRS and HIPEC, and the results showed that NAC did not significantly increase the incidence of severe complications $(24 \%$ vs $17 \%, P=0.55$ ) or mortality ( 0 vs $1.5 \%, P=1.000$ ) [24]. Similarly, Leimkühler et al. observed that the severity and timing of complications were comparable between patients who received NAC and those who did not [17]. Our study also found that patients who underwent NAC were more likely to experience thrombocytopenia after surgery $(30.0 \%$ vs $6.3 \%, P=0.043)$. Moreover, the mean platelet count $\left(151.9\right.$ vs $\left.197.7 \times 10^{9} / \mathrm{L}, P=0.036\right)$ and neutrophil count $\left(4.7\right.$ vs $\left.7.2 \times 10^{9} / \mathrm{L}, P=0.030\right)$ in the NAC group were significantly lower than those in the non-NAC group on POD 1. However, we found that these adverse effects on platelets and neutrophils did not appear to translate into severe postoperative complications $(40.0 \%$ vs $31.3 \%, P=0.519)$.

In theory, NAC can effectively downgrade the primary tumour and peritoneal tumour burden and thus improve long-term survival. In the present study, patients who underwent NAC had significantly lower PCI scores at the time of CRS+HIPEC than those who did not, and a higher proportion of these patients achieved complete cytoreduction (CC 0/1). Moreover, although the CC score, rather than NAC, was independently associated 


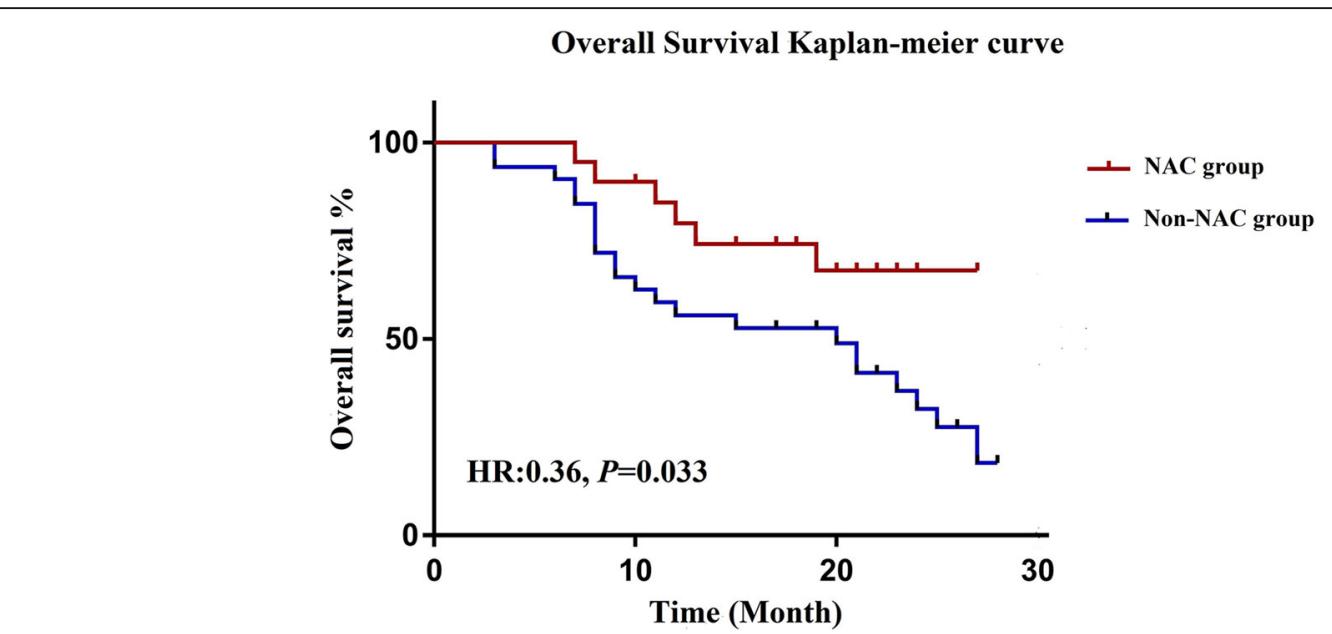

Fig. 6 Overall survival curves for the NAC and non-NAC groups (statistical comparison made by the log-rank test)

with OS in the multivariate analysis, more patients who received NAC survived for 2 years than those who did not $(67.4 \%$ vs $32.2 \%$, respectively, $P=0.044)$. Large-scale multi-institutional registry studies showed that both the PCI score and CC score were associated with long-term survival after CRS+HIPEC $[25,26]$, and the use of NAC to reduce the tumour burden and increase the chances of $\mathrm{CC}$ is an effective and valuable strategy. Consistent with these findings, a retrospective analysis of 298 patients conducted by Beal et al. demonstrated that NAC benefited the survival of patients undergoing CRS+ HIPEC, although NAC was not identified as an independent factor for OS after controlling for confounding factors [13]. Similarly, Devilee et al. reported that treatment with NAC was associated with improved OS before CRS+HIPEC [24].

Several limitations of the current study should be taken into account. The most significant limitation was

Table 4 Univariate and Multivariable Cox Regression Analysis for Overall Survival

\begin{tabular}{|c|c|c|c|c|}
\hline \multirow[t]{3}{*}{ Variable } & \multicolumn{4}{|l|}{ Overall survival } \\
\hline & \multicolumn{2}{|c|}{ Univariate analysis } & \multicolumn{2}{|c|}{ Multivariate analysis } \\
\hline & $\mathrm{HR}(95 \% \mathrm{Cl})$ & $P$ & $\mathrm{HR}(95 \% \mathrm{Cl})$ & $P$ \\
\hline Gender: female/male & $1.13(0.53-2.43)$ & 0.753 & & \\
\hline Age at operation ( $\geq 65$ years $/<65$ years) & $2.12(0.98-4.60)$ & 0.056 & & \\
\hline Preoperative chemotherapy (yes/no) & $0.36(0.13-0.92)$ & 0.033 & $0.55(0.22-1.39)$ & 0.204 \\
\hline T stage $(\mathrm{T} 4 / \mathrm{T} 3)$ & $1.61(0.73-3.54)$ & 0.235 & & \\
\hline \multicolumn{5}{|l|}{ N stage } \\
\hline No & Reference & Reference & & \\
\hline N1 & $1.29(0.57-2.94)$ & 0.545 & & \\
\hline N2 & $2.26(0.71-7.16)$ & 0.167 & & \\
\hline Site of original (rectum/colon) & $1.48(0.63-3.51)$ & 0.373 & & \\
\hline Histology (mucinous/adenocarcinoma) & $2.05(0.96-4.40)$ & 0.065 & & \\
\hline Preoperative CEA level $(\geq 5 \mathrm{ng} / \mathrm{ml} /<5 \mathrm{ng} / \mathrm{ml})$ & $1.68(0.78-3.58)$ & 0.183 & & \\
\hline Liver metastases (yes/no) & $1.24(0.50-3.08)$ & 0.648 & & \\
\hline HIPEC regimen (lobaplatin/non-lobaplatin) & $1.38(0.62-3.05)$ & 0.427 & & \\
\hline Presence of ascites (yes/no) & $1.20(0.55-2.60)$ & 0.650 & & \\
\hline $\mathrm{PCl}$ score $(\geq 12 /<12)$ & $2.98(1.41-6.32)$ & 0.004 & $1.49(0.61-3.66)$ & 0.381 \\
\hline CC score $(2-3 / 0-1)$ & $4.20(1.89-9.36)$ & $<0.001$ & $2.99(1.14-7.84)$ & 0.026 \\
\hline Grade 3-4 postoperative complication (yes/no) & $1.62(0.74-3.57)$ & 0.229 & & \\
\hline
\end{tabular}


the small size, especially in the NAC group, which included only 20 patients; this might have been responsible for some of the observed differences between the two groups. Second, this study was retrospective and had inherent selection bias. Third, vital information, such as KRAS and BRAF mutations, was lacking in some patients, making it difficult to evaluate their prognostic values. Furthermore, the chemotherapy regimens of 20 patients who underwent NAC were not uniform, and some patients were administered targeted drugs such as bevacizumab, which interfered with the prognostic analysis. Finally, the follow-up time of this study was short (median of only 18.5 months), which artificially improved the prognosis. Multicentre, large-sample prospective randomized controlled studies are needed to further confirm our results.

In conclusion, the results of our study demonstrate that NAC prior to CRS+HIPEC had a comparably low mortality rate and an acceptable morbidity rate. Although NAC exerts certain effects on platelets and neutrophils, these effects do not appear to translate to severe postoperative complications. Nevertheless, largesample randomized controlled studies are needed to confirm whether the administration of NAC before CRS+HIPEC confers a survival benefit to patients.

\footnotetext{
Abbreviations

CRC: Colorectal cancer; PM: Peritoneal metastasis; CRS: Cytoreductive surgery; HIPEC: Hyperthermic intraperitoneal chemotherapy; NAC: Neoadjuvant chemotherapy; ECOG: Eastern Cooperative Group; PCI: Peritoneal carcinomatosis index; CC score: Completeness of cytoreduction score; POD: Postoperative day; CTCAE: Common Terminology Criteria for Adverse Events; OS: Overall survival
}

\section{Acknowledgements}

Not applicable.

\section{Authors' contributions}

The authors made the following contributions: (I) conception and design: JWL, SCZ, and WP; (II) administrative support: JWL and WP; (III) provision of study materials or patients: YJJ and WP; (IV) collection and assembly of data: SCZ; and (V) data analysis and interpretation: SCZ, ZXZ and JWL. The authors read and approved the final manuscript.

\section{Funding}

This work was supported by the Capital's Funds for Health Improvement and Research (2016-2-4022) and by a prospective randomized controlled clinical trial of intraoperative intraperitoneal chemotherapy with raltitrexed for the prevention of peritoneal metastases from colorectal cancer in high-risk patients (2020-044-KF). The funders had no role in the design of the study, collection and analysis of the data, or writing of the manuscript.

\section{Availability of data and materials}

While the patient data are confidential, they are available.

\section{Declarations}

\section{Competing interest}

The authors declare that they have no competing interests.

\section{Ethics approval and consent to participate}

The ethics committee of the National Cancer Center/Cancer Hospital, Chinese Academy of Medical Sciences and Peking Union Medical College approved this study. Prior written informed consent was obtained from all study participants.

Consent for publication

Not applicable.

Received: 3 March 2021 Accepted: 30 April 2021

Published online: 17 May 2021

\section{References}

1. National Comprehensive Cancer Network Clinical Practice Guidelines in Oncology. Colon Cancer. Version 2.2019. 2019. Available online: https:// www.nccn.org/professionals/physician_gls/pdf/colon.pdf (Accessed on 1 Nov 2019).

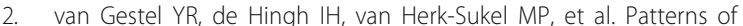
metachronous metastases after curative treatment of colorectal cancer. Cancer Epidemiol. 2014;38(4):448-54. https://doi.org/10.1016/j.canep.2 014.04.004.

3. Lemmens VE, Klaver YL, Verwaal VJ, Rutten HJ, Coebergh JWW, de Hingh $\mid H$. Predictors and survival of synchronous peritoneal carcinomatosis of colorectal origin: a population-based study. Int J Cancer. 2011;128(11):271725. https://doi.org/10.1002/ijc.25596.

4. Kerscher AG, Chua TC, Gasser M, Maeder U, Kunzmann V, Isbert C, et al. Impact of peritoneal carcinomatosis in the disease history of colorectal cancer management: a longitudinal experience of 2406 patients over two decades. Br J Cancer. 2013;108(7):1432-9. https://doi.org/10.1038/ bjc.2013.82.

5. Bushati $M$, Rovers KP, Sommariva A, Sugarbaker PH, Morris DL, Yonemura $Y$, et al. The current practice of cytoreductive surgery and HIPEC for colorectal peritoneal metastases: results of a worldwide web-based survey of the Peritoneal Surface Oncology Group International (PSOGI). Eur J Surg Oncol. 2018;44(12):1942-8. https://doi.org/10.1016/j.ejso.2018.07.003.

6. Quénet F, Elias D, Roca L, Goéré D, Ghouti L, Pocard M, et al. Cytoreductive surgery plus hyperthermic intraperitoneal chemotherapy versus cytoreductive surgery alone for colorectal peritoneal metastases (PRODIGE 7): a multicentre, randomised, open-label, phase 3 trial. Lancet Oncol. 2021; 22(2):256-66. https://doi.org/10.1016/S1470-2045(20)30599-4.

7. Klaver CEL, Wisselink DD, Punt CJA, Snaebjornsson P, Crezee J, Aalbers AGJ, et al. Adjuvant hyperthermic intraperitoneal chemotherapy in patients with locally advanced colon cancer (COLOPEC): a multicentre, open-label, randomised trial. Lancet Gastroenterol Hepatol. 2019;4(10):761-70. https:// doi.org/10.1016/S2468-1253(19)30239-0.

8. Quenet F, Elias D, Roca L, et al. A UNICANCER phase III trial of hyperthermic intra-peritoneal chemotherapy (HIPEC) for colorectal peritoneal carcinomatosis (PC): PRODIGE 7. J Clin Oncol. 2018;36:18.

9. Sluiter NR, Rovers KP, Salhi Y, Vlek SL, Coupé VMH, Verheul HMW, et al. Metachronous peritoneal metastases after adjuvant chemotherapy are associated with poor outcome after cytoreduction and HIPEC. Ann Surg Oncol. 2018;25(8):2347-56. https://doi.org/10.1245/s10434-018-6539-x.

10. Sipok A, Sardi A, Nieroda C, et al. Comparison of survival in patients with isolated peritoneal carcinomatosis from colorectal cancer treated with cytoreduction and melphalan or mitomycin- $C$ as hyperthermic intraperitoneal chemotherapy agent. Int J Surg Oncol. 2018;2018:1920276.

11. Agalar C, Sokmen S, Arslan C, Altay C, Basara I, Canda AE, et al. The impact of sarcopenia on morbidity and long-term survival among patients with peritoneal metastases of colorectal origin treated with cytoreductive surgery and hyperthermic intraperitoneal chemotherapy: a 10-year longitudinal analysis of a single-center experience. Tech Coloproctol. 2020;24(4):301-8. https://doi.org/10.1007/s10151-020-02159-z.

12. Woeste MR, Philips P, Egger ME, et al. Optimal perfusion chemotherapy: a prospective comparison of mitomycin $C$ and oxaliplatin for hyperthermic intraperitoneal chemotherapy in metastatic colon cancer. J Surg Oncol. 2020;121(8):1298 published online ahead of print, 2020 Apr 1.

13. Beal EW, Suarez-Kelly LP, Kimbrough CW, Johnston FM, Greer J, Abbott DE, et al. Impact of neoadjuvant chemotherapy on the outcomes of cytoreductive surgery and hyperthermic intraperitoneal chemotherapy for colorectal peritoneal metastases: a multi-institutional retrospective review. J Clin Med. 2020;9(3):748. https://doi.org/10.3390/jcm9030748.

14. Wong JSM, Tan GHC, Chia CS, Ong J, Ng WY, Teo MCC. The importance of synchronicity in the management of colorectal peritoneal metastases with cytoreductive surgery and hyperthermic intraperitoneal chemotherapy. 
World J Surg Oncol. 2020;18(1):10. https://doi.org/10.1186/s12957-020-1 784-4.

15. Passot G, Vaudoyer D, Cotte E, You B, Isaac S, Noël Gilly F, et al. Progression following neoadjuvant systemic chemotherapy may not be a contraindication to a curative approach for colorectal carcinomatosis. Ann Surg. 2012;256(1):125-9. https://doi.org/10.1097/SLA.0b013e318255486a.

16. Ceelen W, Van Nieuwenhove Y, Putte DV, et al. Neoadjuvant chemotherapy with bevacizumab may improve outcome after cytoreduction and hyperthermic intraperitoneal chemoperfusion (HIPEC) for colorectal carcinomatosis. Ann Surg Oncol. 2014;21(9):3023-8.

17. Leimkühler M, Hemmer PHJ, Reyners AKL, de Groot DJA, van Ginkel RJ, Been LB, et al. Neoadjuvant chemotherapy followed by cytoreductive surgery and hyperthermic intraperitoneal chemotherapy for colorectal cancer: a feasibility and safety study. World J Surg Oncol. 2019;17(1):14. https://doi.org/10.1186/s12957-018-1554-8.

18. Jacquet $\mathrm{P}$, Sugarbaker PH. Clinical research methodologies in diagnosis and staging of patients with peritoneal carcinomatosis. Cancer Treat Res. 1996; 82:359-74. https://doi.org/10.1007/978-1-4613-1247-5_23.

19. Sugarbaker PH. Successful management of microscopic residual disease in large bowel cancer. Cancer Chemother Pharmacol. 1999;43(Suppl):S15-25. https://doi.org/10.1007/s002800051093.

20. Hamashige S, Arquilla ER. Common Terminology Criteria for Adverse Events v3.0 (CTCAE). Principles Pract Clin Trial Med. 2008;42(4):461-533.

21. Pei W, Zhou S, Zhang J, et al. Lobaplatin-based hyperthermic intraperitoneal chemotherapy for patients with peritoneal metastasis from appendiceal and colorectal cancer: safety and efficacy profiles. Cancer Manag Res. 2020; 24(12):12099-110.

22. Chua TC, Morris DL, Saxena A, Esquivel J, Liauw W, Doerfer J, et al. Influence of modern systemic therapies as adjunct to cytoreduction and perioperative intraperitoneal chemotherapy for patients with colorectal peritoneal carcinomatosis: a multicenter study. Ann Surg Oncol. 2011;18(6):1560-7. https://doi.org/10.1245/s10434-010-1522-1.

23. Chua TC, Yan TD, Saxena A, Morris DL. Should the treatment of peritoneal carcinomatosis by cytoreductive surgery and hyperthermic intraperitoneal chemotherapy still be regarded as a highly morbid procedure? A systematic review of morbidity and mortality. Ann Surg. 2009;249(6):900-7. https://doi. org/10.1097/SLA.0b013e3181a45d86.

24. Devilee RA, Simkens GA, van Oudheusden TR, Rutten HJ, Creemers GJ, ten Tije AJ, et al. Increased survival of patients with synchronous colorectal peritoneal metastases receiving preoperative chemotherapy before cytoreductive surgery and hyperthermic intraperitoneal chemotherapy. Ann Surg Oncol. 2016;23(9):2841-8. https://doi.org/10.1245/s10434-016-5214-3.

25. Glehen O, Kwiatkowski F, Sugarbaker PH, Elias D, Levine EA, de Simone M, et al. Cytoreductive surgery combined with perioperative intraperitoneal chemotherapy for the management of peritoneal carcinomatosis from colorectal cancer: a multi-institutional study. J Clin Oncol. 2004;22(16):328492. https://doi.org/10.1200/JCO.2004.10.012.

26. Elias D, Gilly F, Boutitie F, Quenet F, Bereder JM, Mansvelt B, et al. Peritoneal colorectal carcinomatosis treated with surgery and perioperative intraperitoneal chemotherapy: retrospective analysis of 523 patients from a multicentric French study. J Clin Oncol. 2010;28(1):63-8. https://doi.org/1 $0.1200 / \mathrm{JCO} .2009 .23 .9285$

\section{Publisher's Note}

Springer Nature remains neutral with regard to jurisdictional claims in published maps and institutional affiliations.

Ready to submit your research? Choose BMC and benefit from:

- fast, convenient online submission

- thorough peer review by experienced researchers in your field

- rapid publication on acceptance

- support for research data, including large and complex data types

- gold Open Access which fosters wider collaboration and increased citations

- maximum visibility for your research: over $100 \mathrm{M}$ website views per year

At BMC, research is always in progress.

Learn more biomedcentral.com/submissions 